\title{
ФОРСТЕРИТСОДЕРЖАЩИЙ ОГНЕУПОР ИЗ ОТХОДОВ ПРОИЗВОДСТВА КОВДОРСКОГО ГОРНО-ОБОГАТИТЕЛЬНОГО КОМБИНАТА
}

\section{Белогурова О.А., Саварина М.А., Шарай Т.В.}

Институт химии и технологии редкоземельных элементов и минерального сырья им. И.В Тананаева КНЦ PAH, Anamumbl, belog_oa@chemy.kolasc.net.ru

Успешный опыт промышленного использования «лежалых» отходов обогащения руд, его высокая технологическая, экономическая и экологическая эффективность стали основанием для перехода от бытующего (формального) отношения к отходам горнорудного производства как экологически вредным скоплениям к включению их в состав стратегических перспективных минерально-сырьевых ресурсов управляющей компании и Ковдорского ГОКа. По «генезису» и форме накопления технологические отходы горнорудного производства можно условно разделить на две группы - «мокрые» и «сухие». На Ковдорском ГОКе к первой группе относятся уложенные в хвостохранилище отходы обогатительного производства: мелкие сильнообводненные пески, содержащие остаточные концентрации основных полезных компонентов, а также не извлеченные в производственном процессе по технологическим, экономическим или конъюнктурным причинам ценные или потенциально ценные примеси (например, минерал форстерит с содержанием до 50 \% $\mathrm{MgO}$ ). Ко второй группе отнесены отвалы-склады бедных и забалансовых руд разрабатываемых месторождений» [3].

Необходимость существенного расширения производства и применения форстеритовых огнеупоров обусловлена высокой температурой плавления форстерита $\left(1890{ }^{\circ} \mathrm{C}\right)$, шлако- и металлоустойчивостью. Широкое использование их в промышленности сдерживает низкая термостойкость.

Цель работы - получить термостойкий огнеупорный материал на основе форстеритового концентрата из отходов обогатительного производства Ковдорского ГОКа.

Задачи:

- разработать технологию термостойких форстеритоуглеродистых материалов;

- оценить степень влияния химического и гранулометрического составов исходных материалов (концентрата, брикета и добавок) на свойства форстеритовых огнеупоров;

- установить зависимость технических характеристик огнеупора от температуры обжига брикета.

Химический анализ форстеритового концентрата из отходов обогатительного производства по главным оксидам, мас. \%: $\mathrm{MgO}$ - 42.0; $\mathrm{SiO}_{2}-30.6 ; \mathrm{FeO}-5.30 ; \mathrm{Fe}_{2} \mathrm{O}_{3}-5.91, \mathrm{CaO}$ - 2.40; п.п.п. - 0.11. В подчиненных количествах в структуру могут входить катионы $\mathrm{Al}^{3+}$ и $\mathrm{Mn}^{2+}$. Поведение магнезиальносиликатного сырья при обжиге зависит от степени его чистоты.

Размеры зерен форстеритового концентрата из отходов обогатительного производства находятся в узком диапазоне значений - 0.2-0 мм. Большая часть примесных минералов находится в сростках, келифитовых каймах, в промежутках между трещинами в зернах. В форстерите из апатито-форстерито-магнетитовых пород Ковдорского массива присутствует от 3 до 8 \% фаялитового компонента [4].

Изучение морфологической картины поверхности проводилось на сканирующем электронном микроскопе SEM LEO 420 (CARL ZEISS, Германия). Качественный и количественный состав локальных участков образцов получен рентгеноспектральным микрозондовым анализом (PMA) при помощи энергодисперсионной микрозондовой приставки INCA Energy 400 (OXFORD Instruments, Великобритания). Обнаружено, что после термической обработки концентрата при $1450^{\circ} \mathrm{C}$ появляются фазы спектрально схожие по составу на бронзит, гиперстен, диопсид и пироп. Для уменьшения влияния примесей и повышения огнеупорных свойств материала к форстеритовому концентрату, полученному из отходов обогатительного производства Ковдорского ГОКа, необходимо добавлять оксид магния, в данной работе использован бой магнезитовых изделий. 
В технологии форстеритовых огнеупоров предпочтителен следующий гранулометрический состав шихты: до 55 мас. \% фракции 3-0.63 мм, до 40 мас. \% фракции менее 0.1 мм. Следовательно, для сырого форстеритового концентрата, гранулометрический состав которого находится в диапазоне 0.2-0 мм, требуется брикетирование.

Составы брикета: № 1 - 100\% форстеритовый концентрат, № $8-60 \%$ фр. 0.2-0 мм и $15 \%$ фр. $<0.063$ мм форстеритового концентрата и $25 \%$ боя магнезитовых изделий фр. 3-0.2 мм; № 8.1 $50 \%$ фр. 0.2-0 мм и $15 \%$ фр. $<0.063$ мм форстеритового концентрата и $35 \%$ боя магнезитовых изделий фр. 3-0.2 мм.

Технологическая схема получения брикета: шихта определенного состава из форстеритового концентрата фракции 0.2-0 мм, боя магнезитовых изделий фракции 3-0.2 мм перемешивается, вводится связка (поливиниловый спирт), прессуется под давлением 50-70 МПа, высушивается в естественных условиях в течение суток. Затем обжигается при температурах $1300,1400,1450^{\circ} \mathrm{C}$. Полученный брикет дробят с получением фракций 3-0 мм, часть подвергают помолу на виброистирателе ИВ 1 , для получения фракции менее 0.063 мм. При получении брикета из форстеритового концентрата определяли влияние состава шихты и температуры обжига на его свойства.

Установлена зависимость основных свойств брикета от состава шихты (рис. 1). Для образцов всех составов брикета, обожженных при $1300,1400,1450^{\circ} \mathrm{C}$, термостойкость составила одну теплосмену.

В легенде состав шихты из сырого форстеритового концентрата с добавлением вибромолотой фракции (*) и боя магнезитовых изделий (б), мас.\%.

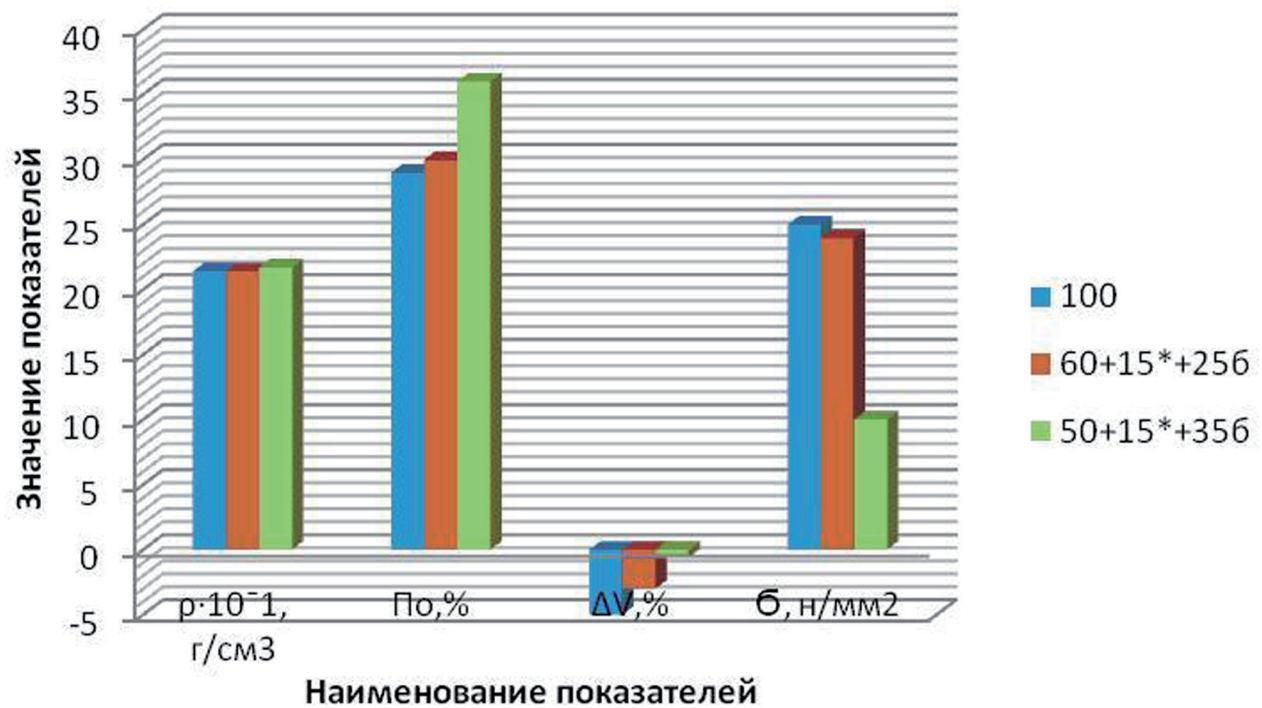

Рис. 1. Сравнительная гистограмма свойств брикета из форстеритового концентрата, обожженного при $1400^{\circ} \mathrm{C}$. $\rho$-плотность, По - пористость, $\Delta \mathrm{V}$ - изменение объема, 6 - прочность.

Введение углерода в шихту для получения форстеритового огнеупора повышает теплопроводность и снижает коэффициент линейного расширения тем самым, увеличивая термостойкость. Ранее в наших исследованиях были получены форстеритоуглеродистые огнеупоры из оливинита Хабозера с использованием ряда антиоксидантов $[1,2]$.

Построены гистограммы зависимости свойств образцов на основе брикетов № 1,8 и 8.1 идентичных составов от температуры его обжига (рис. 2-4).

Для форстеритоуглеродистых образцов на основе брикета разного состава показатели плотности и изменения объема практически неизменны, открытой пористости и водопоглощения уменьшаются, термостойкости и прочности увеличиваются с повышением температуры обжига. Анализ данных показывает, что в форстеритовый концентрат необходимо вводить до $35 \%$ боя магнезито- 


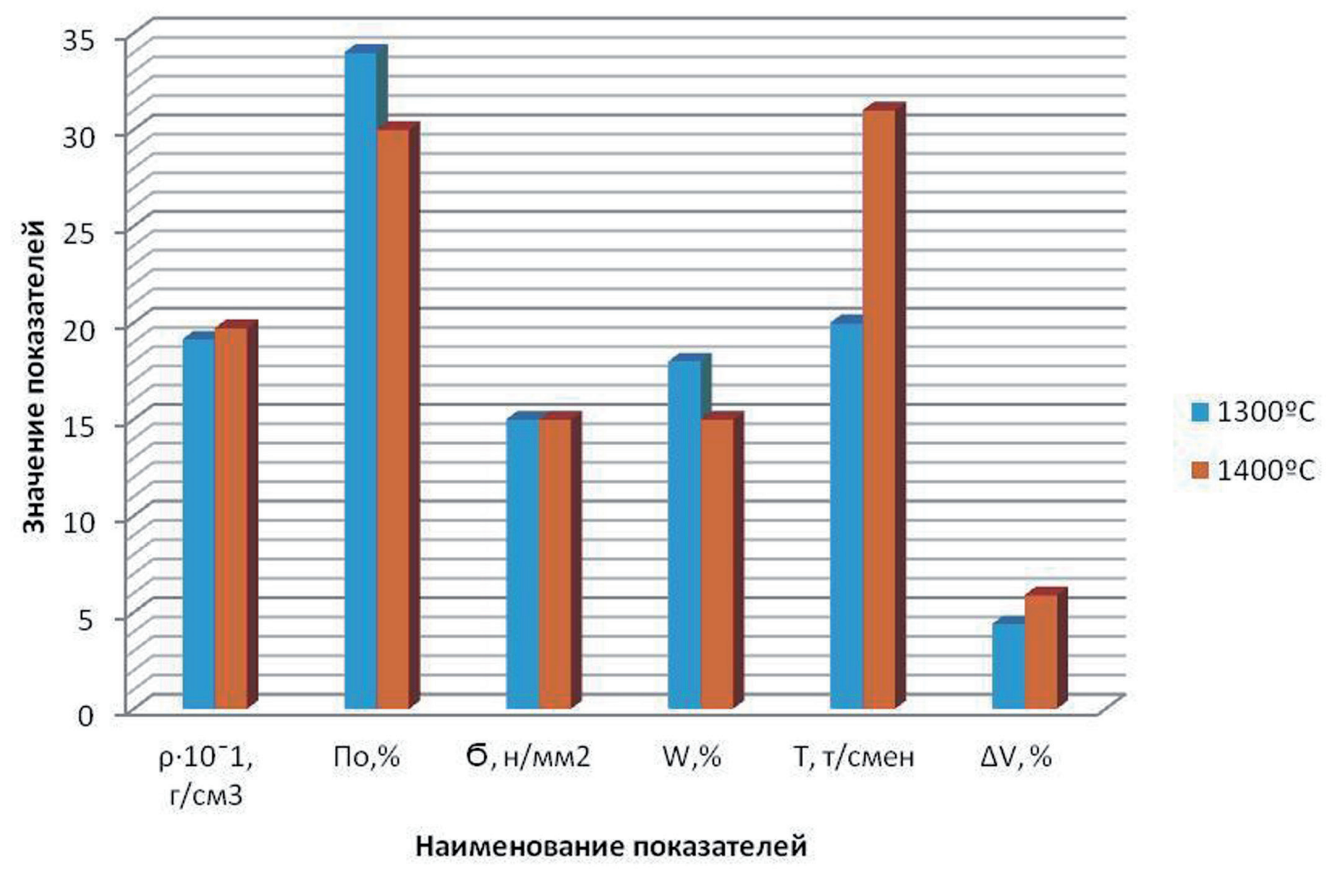

Рис. 2. Свойства форстеритоуглеродистых образцов на основе брикета № 1, обожженного при $1300^{\circ} \mathrm{C}$ и $1400^{\circ} \mathrm{C}$. $\rho$ - плотность, По - пористость, б - прочность, W - водопоглощение, $\mathrm{T}$ - термостойкость $\left(1300^{\circ} \mathrm{C}\right.$ - вода), $\Delta \mathrm{V}$ - изменение объема.

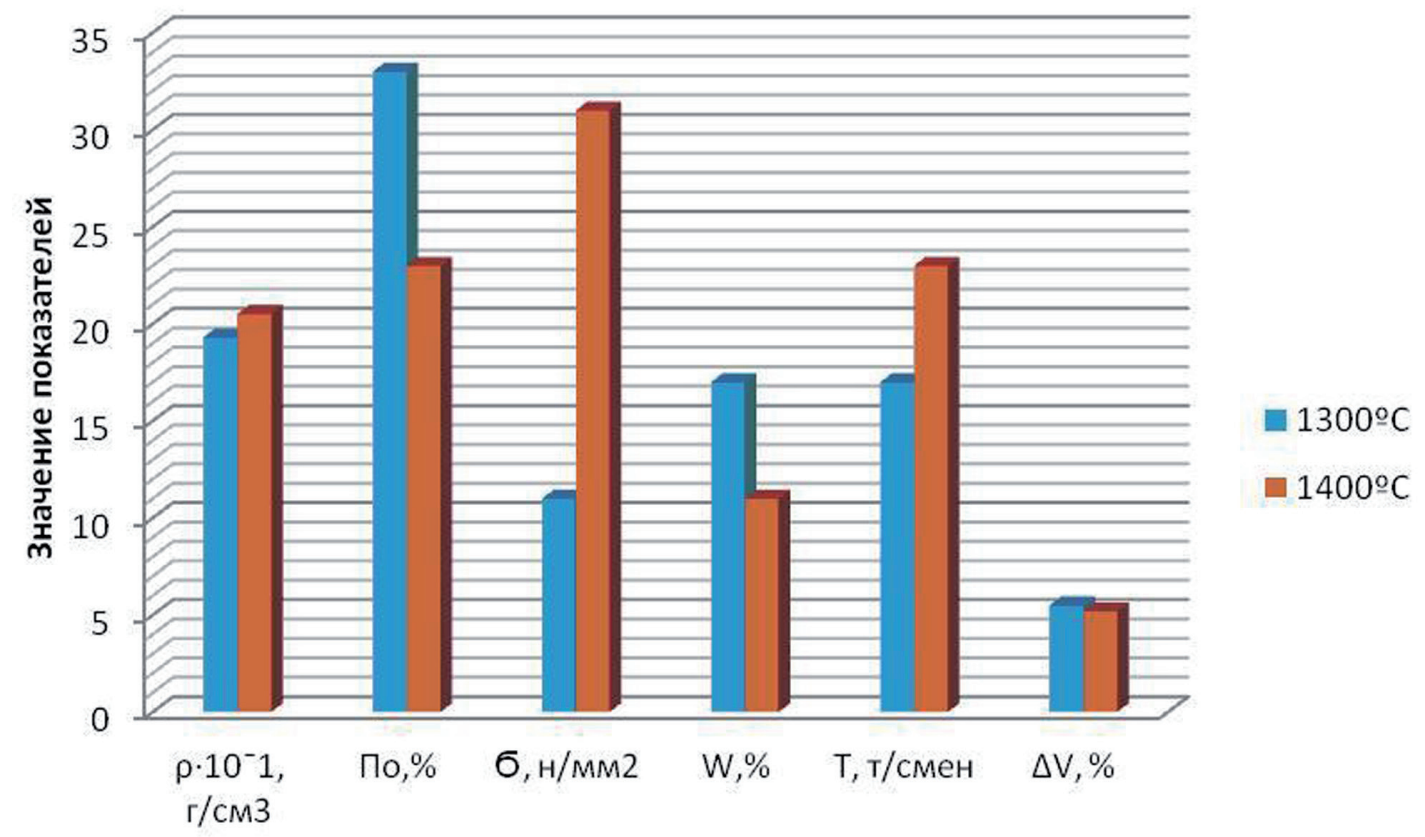

Наименование показателей

Рис. 3. Свойства форстеритоуглеродистых образцов на основе брикета № 8, обожженного при $1300^{\circ} \mathrm{C}$ и $1400^{\circ} \mathrm{C}$. $\rho$ - плотность, По - пористость, б - прочность, W - водопоглощение, $\mathrm{T}$ - термостойкость $\left(1300^{\circ} \mathrm{C}-\right.$ вода), $\Delta \mathrm{V}$ - изменение объема.

вых изделий. Установлено, что состав шихты, а именно, количество фракции брикета из форстеритового концентрата менее 0.063 мм и фракции 3-0.2 мм боя магнезитовых изделий, влияют достаточно эффективно на все физико-технические свойства (рис. 2-4). Максимальный показатель тер- 


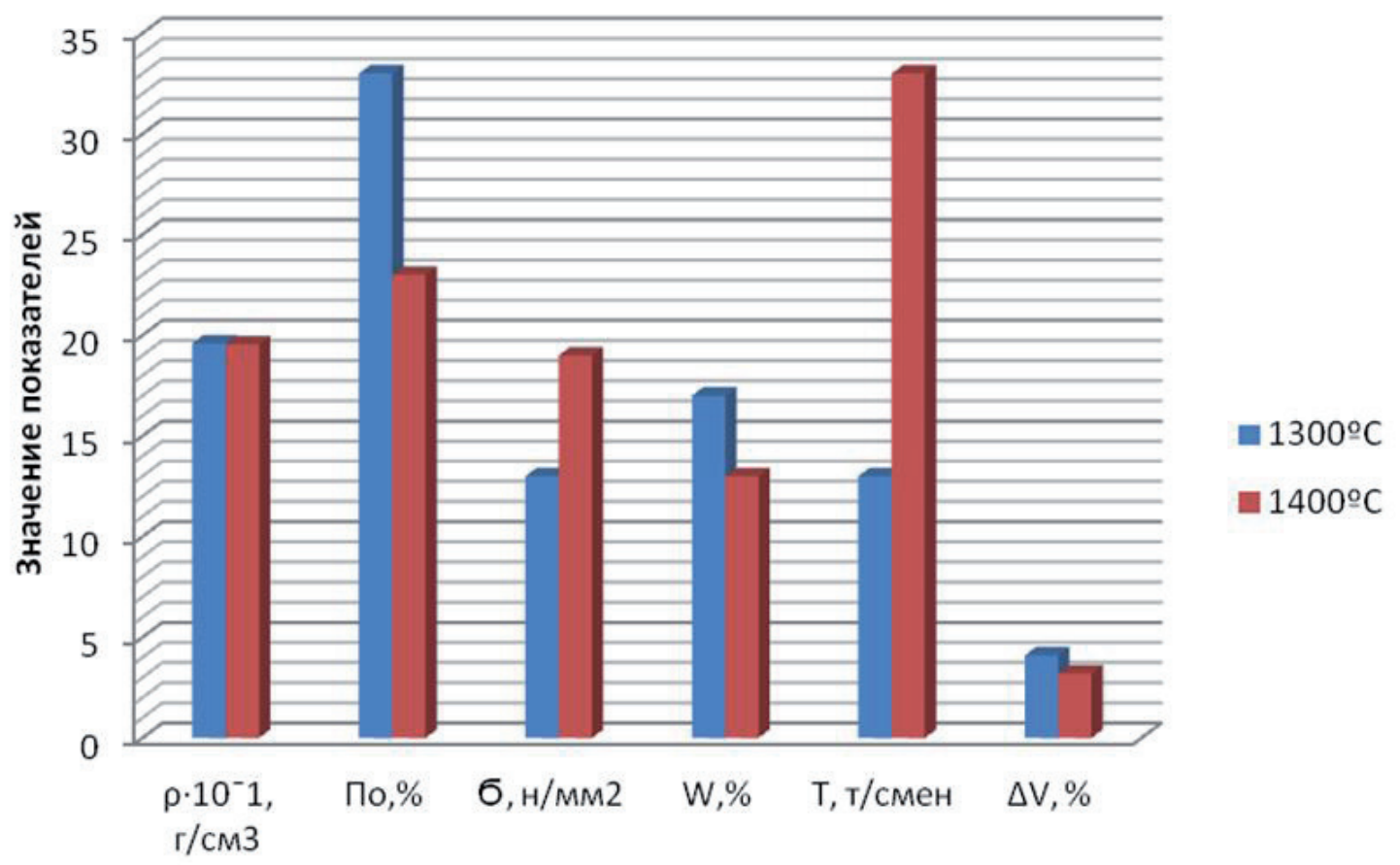

Наименование показателей

Рис. 4. Свойства форстеритоуглеродистых образцов на основе брикета № 8.1, обожженного при $1300^{\circ} \mathrm{C}$ и $1400^{\circ} \mathrm{C}$. $\rho$ - плотность, По - пористость, б - прочность, W - водопоглощение, $\mathrm{T}$ - термостойкость $\left(1300^{\circ} \mathrm{C}-\right.$ вода $), \Delta \mathrm{V}$ - изменение объема.

мостойкости был получен для форстеритоуглеродистых образцов из шихты, содержащей брикет на основе форстеритового концентрата, с введением его тонкомолотой составляющей, и 35 мас. \% боя магнезитовых изделий.

\section{Литература}

1. Гришин Н.Н., Белогурова О.А. Разработка термостойкого форстеритового огнеупора на основании модели влияния теплопроводности на термическое разрушение футеровок // Новые огнеупоры. 2006. № 5. C. $32-35$.

2. Гришин Н.Н., Белогурова О.А. Влияние структурирующих добавок на термостойкость форстеритовых огнеупоров // Огнеупоры и техническая керамика. 2007. № 9. С. 3-8.

3. Петрик А.И., Быховец А.Н., Сохарев В.А., Переин В.Н., Сердюков А.П. Модернизация минеральносырьевой базы в стратегии долгосрочного развития Ковдорского ГОКа // Горный журнал. 2012. № 10. C. 12-17.

4. Римская-Корсакова О.М., Краснова Н.И. Геология месторождений Ковдорского массива. СПб.:Изд-во С.-Петерб.ун-та. 2002. 146 с. 